\title{
Staff Perspectives of a Café on the Premises of an Aged Care Facility
}

\author{
Alexa Andrew ${ }^{1 *}$, Aimee Foot McKay ${ }^{2}$ and Lorraine Ritchie ${ }^{3}$ \\ ${ }^{1}$ Senior Occupational Therapy Lecturer, Otago Polytechnic, New Zealand \\ ${ }^{2}$ Occupational Therapist, Insight, Laura Fergusson Trust, New Zealand \\ ${ }^{3}$ Professional Nursing Advisor, New Zealand Nurses Organisation, New Zealand \\ *Corresponding author: Alexa Andrew, Senior Occupational Therapy Lecturer, Otago Polytechnic Private Bag 1910, Dunedin 9010, New Zealand
}

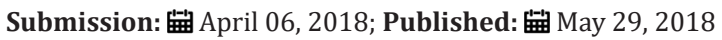

\begin{abstract}
Aim: To explore the value of a café at an aged care facility from staff members' perspectives.

Background: A contemporary approach in residential aged care known as 'person centered care', acknowledges the resident as a person who has individual needs, desires, interests and values who is part of a family and wider social network. At the heart of 'person centered care' is the relationship between the staff member and the resident which is encouraged to be meaningful, empathetic and reciprocal. A focus on the relational aspects of care indicates that the environment of residential aged care facilities needs to offer social and interactive spaces designed to provide a more homelike environment and facilitate the development of meaningful relationships. A café environment and the activity of going to a café are inherently social and have the potential to contribute to the fulfilment of 'person centered care' where relationships are valued. The café, which was the subject of this research, is part of a large aged care facility and was established during a process of major renovation. The café was designed to be used by residents, their family and friends, the staff and the public.
\end{abstract}

Methods: Semi-structured interviews were conducted with nine staff members from a variety of work roles in 2015. The study employed qualitative descriptive methodology and data was analyzed using thematic analysis.

Result: The findings of the participants' narratives illustrated that the café has become an integral part of their daily lives at work. Three key themes were established; "Creating and supporting relationships". "Space and place", and "Staff celebrations and functions". The relational aspects of care are fostered and enhanced by the social opportunities facilitated by the café. Staff meet with residents, families and other staff to carry out work responsibilities as well as taking the opportunity to socialize informally. The physical and social environment of the café generates an atmosphere which provides opportunities for staff to experience relaxation, rejuvenation and feel a sense of belonging. Staff lives are valued when events to celebrate achievements and milestones are held.

Conclusion: The inclusion of a café in an aged care facility has the potential to facilitate positive benefits for the staff that work there and therefore improve their experience of work and sense of job satisfaction.

Keywords: Residential aged care; Culture change; Environment; Staff perspectives; Relationships; Staff satisfaction

\section{Introduction}

The ageing population throughout the western world has resulted in increased attention being paid to the residential aged care sector. Traditional aged care residential facilities (ACRF) were designed in alliance with a medical model of care and would resemble a hospital where nursing stations, sluice rooms and shared bedrooms and bathrooms predominated. Today perspectives towards the design of residential aged care are changing with a central focus being placed on the residence as being the older persons' home. This shift in perspective, which has been labeled as 'culture change', identifies the physical and social environment as a resource to improve the quality of life for the residents [1]. The majority of research to date has assessed the impact of culture change initiatives on various resident outcomes. Less attention has been paid to outcomes for staff, who play a vital role in the delivery of culture change principles. This article reports on staff perspectives of one specific environmental innovation which was the inclusion of a café in an aged care facility.

The café referred to in this research was established in a large 123 bed ACRF during a process of major redesign and renovation. This large ACRF has five different units; two rest-home level care, 
two hospital level care and one dementia care, each with its own dining area where residents eat their meals provided by the kitchen of the facility. Each unit also has a lounge area and other small visiting areas. The café is situated in the foyer at the front entrance of the ACRF and is open seven days a week from 9.45am to $4 \mathrm{pm}$ and services the residents of the facility, their family and friends as well as being open to the public. The café consists of 3distinct areas; indoor tables and chairs, comfortable couches in front of a fireplace and an outdoor courtyard. The view from the café is the foyer of the ACRF, where the comings and goings of the facility are easily seen. The menu at the café offers barista coffee, tea, a variety of light meals, sandwiches and cakes, and is priced just below market rates.

The café is funded and supervised by the management of the ACRF. The café offers a service which is in addition to the meal service the residents receive daily in the residential care environment. The researcher, an occupational therapist by profession, envisaged a number of benefits of a café on the premises of an ACRF. However, the researcher acknowledges her bias due to professional enculturation and was interested in discovering the value from the café users' perspectives. This article reports on phase two of a research project; the first phase explored the value of the café from the perspective of the residents and their family and friends [2].

Achieving a more home-like environment in ACRF's has been implemented in a variety of ways over recent years. The Green House Model focuses on the built environment where residents live in ordinary sized residential housing in neighbourhoods, both of which have been adapted to accommodate the needs of older people [3]. The Eden Alternative includes transforming the physical environment into a human habitat where residents have close contact with plants, animals and children [4], and the Wellspring Model pays primary attention to transforming the culture of care which respects and values each resident and employee [5]. A revolutionary model of dementia care developed in the Netherlands consists of a purpose built village where each house is modeled on one of the seven types of Dutch lifestyle, and also includes a town square, supermarket, café, pub and theater. Residents are able to go about their daily lives carrying out familiar everyday activities and roam freely and safely in the village [6]. While formal culture change models have a defined focus, implementing culture change usually includes several approaches; transformation of the built environment, implementation of 'person centered care' (PCC) and changes to staff roles and/or structure to enable the delivery of a change in the culture of care.

Research on the impact of culture change initiatives, to date, has naturally prioritized resident outcomes. The Green House Model [7] and the Eden Alternative [8] have both produced positive results on a variety of resident outcomes. However, more recent systematic reviews of culture change are inconclusive [1,9-11]. Grabowski et al. [9], who conducted a large-scale longitudinal evaluation of the association between culture change and quality of care, point out that while there are common dimensions in approaches to culture change, the degree of variation which exists makes it difficult to identify the elements of culture which account for positive results. Therefore it is difficult to determine whether environmental innovations or approaches to care are instrumental. Evaluations of the impact of individual environmental innovations on residents have included; renovation of outdoor spaces [12], dining areas [13] and inclusion of a cafe [2].

The majority of research focused on staff outcomes has been conducted with frontline workers i.e. nurses and care workers and has been based on principles of culture change namely PCC, rather than specific environmental enhancements. Studies have examined; staff comfort levels with concepts of PCC [14], the relationship between staff job satisfaction and PCC [15], and the relationship between perceptions of psychosocial work climate, job strain, and PCC [16]. Studies which explore the job satisfaction of staff are integral to achieving resident satisfaction due to the established link between them [17].

The single piece of research which specifically explored the impact of the design of the physical environmental on staff was unrelated to culture change. Rigby \& O'Connor [6] examined the impact of the physical environment on retaining older workers in aged care residential facilities (ACRF). Older workers experienced specific challenges in the workplace and participants reported that; constant walking between residents' rooms in long corridors was tiring, heavy equipment was difficult to move and cluttered work spaces hindered their ability [6].

Further research with a focus on staff has investigated staff responses to culture change and has produced opposing results. On the one hand, implementation of culture change has been met with resistance from long term staff who appear to have an established mind set, do not see a need for change and fear an increase in their workload [18-20]. On the other hand, culture change has also been identified as a contributor to successful retention of staff [20]. The plight of the staff in the aged care industry is well known and documented. Care worker staff have high resident to staff ratios, receive inadequate training and benefits and have limited career options [21]. Similar evidence exists regarding nursing staff in the aged care sector [22] and the recruitment and retention of health care staff poses a significant challenge [21]. Culture change provides an important opportunity for the aged care industry to overhaul the care of older people but also to improve the place and experience of work for staff.

Determining the value of the café for staff provides an important perspective on what contributes to job satisfaction for nursing and care worker staff, which in turn can impact on resident satisfaction. The rationale to recruit all staff as potential participants was based on the lack of literature which represents the perspectives of staff other than frontline workers.

\section{Methods}

This research utilized qualitative inquiry of a descriptive nature which was developed through a need to provide a pragmatic and contextualized approach that translates easily back into the practice 
setting [23]. Qualitative methodology was appropriate in that it facilitated meaning enriched expression from the participants through the use of semi-structured interviews.

\section{Participant Recruitment}

Potential participants consisted of all staff at the ACRF whether they had direct involvement with resident care or not. There are approximately 180 staff employed at this ACRF; approximately 88 are nursing, caring and allied health professionals and the remaining 82 are service related eg housekeeping, laundry and kitchen staff. Initially recruitment occurred through an advertisement in the aged care facilities fortnightly staff newsletter, at this point 3staff members were recruited. To gain further participants, posters inviting staff to participate were distributed throughout the ACRF. Inclusion criteria consisted of all staff members employed by the ACRF where the café was situated. There were nine participants interviewed, three males and six females, who were employed in a variety of positions; care workers (two), healthcare professional (one), housekeeping (one), administration (two), maintenance (one), chaplaincy (one)and food service (one). Written informed consent was gained from all participants and anonymity was ensured through use of pseudonyms and removing any data that may render the participant identifiable to others. The study was approved by The Otago Polytechnic Ethics Committee.

\section{Data Gathering}

Eight semi-structured interviews were conducted onsite at the ACRF either in the café or in a meeting room. Two of the participants elected to be interviewed together. The interviews were conducted during work hours with the permission of the ACRF manager and the time set was at the discretion of the participant so as not to interfere with their work duties. The interviews were conducted by an honor's candidate under the supervision of the primary researcher who conducted phase one of this research project. Neither of these people are employed by the facility where the café is situated. The interviews were guided by a core set of five questions, which explored the participants' perceived value of the café, and prompts that were formulated by the interviewer. To warm-up the interview participants were asked how often they use the café and for what reason. To follow participants were asked, what are your perspectives on having a café here at (name of facility)? From that point the interviewer used various prompts to clarify and explore the participants' perspectives. A pilot interview to trial the questions/prompts was conducted and supervision with the primary researcher/supervisor occurred prior to finalizing the questions. Interviews were audio recorded. The interviewer felt confident that data saturation was reached after the eight interviews.

\section{Data Analysis}

Data analysis occurred according to the stages outlined by Marshall \& Rossman [24]; organizing the data, immersion in the data, coding the data, writing analytic memos and generation of themes. Stage one consisted of organizing the data and transcription of the interviews which was carried out by the honor's candidate and therefore resulted in gaining an appreciation of the data as a whole. Stage two, immersion in the data, involved reading and re-reading the transcripts until in depth familiarity occurred. The third stage of coding included highlighting sections of interest in the transcript and writing analytic notes in the margin of the pages indicating potential links or similarity between excerpts of data. Codes were grouped into initial themes, using a system of post-itnotes to visually organise the data. This iterative process continued with review, revision and visual re-clustering of codes until themes and sub-themes were finalised [24]. Peer examination occurred to check the fit between data and established themes on two occasions. Firstly peer examination occurred in supervision sessions between the honor's candidate and the primary researcher of phase one, secondly, opportunities for peer discussion occurred during honor's school sessions with senior lecturer/researchers and peer honor's students. Careful attention is paid during this process to protect participants' identities.

\section{Findings}

The staff interviewed identified the value of the café for themselves as well as for the residents and their families. The value of the café for residents from the perspectives of staff demonstrated considerable similarity to the results of phase one of this research and have been discussed in a previous publication [2]. Therefore, the remaining interview data which summarized the findings of the value for staff are presented according to three key themes; 'Creating and supporting relationships', 'Space and place' and 'Staff celebrations and functions'.

\section{Creating and Supporting Relationships}

Staff members consistently referred to the way the café facilitates the creation and maintenance of a variety of different relationships; among staff members, residents, family members, and others from outside the facility.

\section{Work Relationships}

The café is a place for congregating with other staff members and is described as an effective environment for workplace conversation and reflection. "We usually go as a group,...it's a really good place to congregate and have a good wee natter (chat) and if there are any problems in the place or whatever is going on". The café facilitated connections between staff members in different departments who may not have otherwise spent much time together. "Yeah, I mean there's staff from other areas that meet here which is quite, you know, it's not like, it doesn't get people segregated .... Staff also meet with business representatives who provide services at the aged care facility and discuss business over a cup of coffee. "And even business people that come like the lady that I buy the uniforms off - um she comes from (name of city), we, I, always make a point of inviting her for coffee".

\section{Social Relationships}

Social relationships were also fostered within the café 
environment. "You always know that people are going to stop and chat and hardly anyone walks past there and ignores you". "It's quite good to catch up with other staff too in other departments, that sometimes we meet up and have a catch up at lunch time. It's quite good to get to know other people". Staff members are also able to meet with their own friends and families. "I've also met with family and friends here at lunchtime, and my own mum and dad have been in a few times and had lunch".

\section{Engagement with Residents and Families}

The café was described as a place to meet with residents and their families to carry out tasks related to the staff member's role. "In regarding my job, I believe café offers me a great venue where I can meet people. You can't take relatives or someone to the staff room to talk to them... the café gives you a good opportunity to have a chat". The café is also used by staff who facilitate leisure activities with residents and is valued as a destination "...often the activities staff will bring a group of residents to the café" Engagement with residents and their families was also social in nature. Invitations sometimes occur spontaneously; "I get invited sometimes, when residents or families see me there, sometimes I sit down and chat for a minute".

\section{Place and Space}

\section{Physical and sensory elements}

The physical environmental features of the café appreciated by staff were sensory and design related. The strong smell of coffee arising from the café was described as an enjoyable smell. "You can walk past and there is that really strong aroma of coffee, and it makes you think, oh that smells good." The physical design of the environment was described in terms of the warmth it offers i.e. a courtyard available for eating outside and a fire inside for colder weather. "It's quite a nice wee environment, and its relaxing, it's really nice to be able to sit out in the courtyard, it's quite hot out there, and the fire gives you that kind of cozy feeling; something about seeing the flames - psychologically pleasing."

\section{Atmosphere}

The atmosphere generated by the presence of the café was appreciated from a variety of perspectives; some staff saw it as a relaxing place for time out others appreciated the lively atmosphere it generates. The café is perceived as a place for staff to relax and have 'time out' from the fast paced workday. "When you come to café, it's almost like you step out from your workplace, it's a little bit more relaxed atmosphere." The café is situated in the front foyer of the facility and creates a hub of constant activity which contributes towards an atmosphere of liveliness within the core of the facility. Staff clearly value the lively atmosphere of the café - in this quotation the mood of the foyer was described when the café is closed. "The other day it snowed ... everyone panics, you know... and she came in and we opened from 11-2 but before it was open it was like a ghost town in this area." The friendly welcoming atmosphere was also highlighted. "It gives it a, it gives it kind of a friendly kind of atmosphere".
This staff member appreciated the variety available in the café which contributed to the atmosphere, "Whereas here, you can sit and chat to people or just sit in your own wee world and there is usually a newspaper that you can grab if you want to do that and get a coffee or whatever. It's just a nice atmosphere". As well as positive environmental elements, it is important to note that a number of the participants presented suggestions as to how the environment within the café could be improved. "I think here, they need a sunshade in the wee courtyard-y bit... some sort of shade out there would be good". "They need double doors at the front to stop the wind, the cold wind blowing through the café when people are sitting there, that's the only downside I can see".

\section{Staff celebrations and functions}

The café offers a convenient and pleasant place for staff to celebrate work related, personal or annual events. "And sometimes if a staff member is having a birthday, we might call people in and have a coffee in the café for morning tea just to celebrate if someone's leaving or Christmas times ...". The café is also a place in which fundraisers occur where staff members can support various charities. "We've actually had staff functions, it was the breast cancer awareness week, they did a breakfast which we paid and made a donation".

The café is also used by staff members to buy lunch, morning tea or treat themselves; one staff member described the coffee card system and the sense of achievement that she gains from getting a free coffee. "I mean the coffee and that here, is so much cheaper than the coffee out there. And we've got our wee cards that we can use and they stamp them and that, and you feel really good when you are getting a free coffee!" The manager of the facility uses the café as a resource to provide workplace rewards and incentives for staff. "Our manager will often say to a group of people that she maybe doesn't see all that often ... we'll meet up at the café for a coffee, ... she uses it as a reward".

\section{Discussion}

Environmental innovations occurring as part of culture change in an ACRF provide an opportunity to improve the working environment of staff, evidence suggests that the work environment in an ACRF is an important determinant of job satisfaction [16]. The dominant theme of the findings of this research focused on the social environment and the opportunities created by the café for engaging in a variety of relationships. Staff described the value of being able to engage with residents and their families in the café environment in both social and work related roles. Meaningful positive relationships with residents is a commonly cited factor in influencing retention of nursing and care worker staff [22]. Marquiz \& Hoogland [25] concur and highlight that respecting "the relational context of aged care" is one of the most important factors in staff retention (p.10). The long-term relationships between the staff and the residents in residential aged care are unique and recognized as having the capacity to enrich both parties [26,27], therefore what is beneficial for staff is also of benefit to residents. Improving job 
satisfaction for staff in ACRF's is linked to resident satisfaction and Boldy, Chou \& Lee [28] suggest that the "...greatest potential for increasing the satisfaction of residents appears to be by attending to factors which influence staff satisfaction... [29]".

Relationships with other staff, being part of a team and the development of a sense of belonging to a community are also cited as important to job satisfaction [22]. The café creates a welcoming atmosphere where congregate and discuss workplace issues. Haggstrom \& Kihlgren [30] concur that support and opportunities to discuss problems improves staff satisfaction. Chou \& Lee [28] identify that the nurse manager is pivotal to team cohesion and should be instrumental in developing a stable and friendly environment for staff. The nurse manager in this facility is a regular user of the café and this contributes to the profile of a manager who is visible and accessible. Creating a sense of community, as part of culture change, is relevant to all staff in an aged care facility and perhaps one of the most fundamental attributes of the café is that it services all staff and residents and is an environment where the position of the person is not important - as was illustrated by this quote "it doesn't get people segregated". The café provides a place where all people, from within the ACRF and the local community gather for coffee, conversation, and the fundamental human need of connecting with others [31].

The unique work of directly caring for residents can result in a dichotomy of experiences; it can be physically demanding, emotionally draining, yet rewarding and enriching and there is no doubt that staff who do this work need to feel valued. The café provides staff with a variety of opportunities for rejuvenation and reward; a place to take time out, appreciate the inherent sensory experiences present in the café environment and consume food and drink at times paid for by the manager in recognition of a job well done. The café also offers a place where celebrations for staff members can be held whether they are personal such as birthdays or work related such as gaining a qualification. Lack of recognition was seen as impacting on mental health of care workers [29] and the experience of being valued and recognized for their caring abilities was instrumental in retention of staff [25].

When staff related outcomes have been included in research focused on ACRF's they are always inevitably the frontline workers - those who are directly involved in the physical and nursing care of the residents. The importance of this group is undeniable; however, there are many other staff members in an aged care facility who make up the community of people who engage with the physical and social environment on a daily basis, for example reception staff, kitchen staff, domestic staff and maintenance workers. This research has attempted to incorporate the perspectives of all staff from the viewpoint that changes to the environment as part of culture change must impact on the experience of work for all staff not just frontline workers. The importance of each individual staff member, no matter which department or role they are associated with, is acknowledged by the Wellspring Model of culture change.
Staff from all departments participate in education and staff empowerment is a key principle of this model of culture change [5], one example cited by Stone et al. [20] is the formal inclusion of maintenance staff into the clinical team. During the course of their work maintenance staff observe residents who are at a risk of falling and have been trained to assist residents to stand safely. Kehoe \& Van Heesch [5] suggest that individuals who work in aged care facilities are there because they want to make a difference rather than for the pay. Anecdotal evidence suggests that the staff who service the facility also value their relationships with residents, and residents benefit from reciprocal relationships with a variety of staff who all have unique attributes to offer.

\section{Clinical Implications}

This research contributes to knowledge about the potential design options for new or renovated aged care facilities. Nursing staff/managers and other multi-disciplinary team members are often involved in the consultation process of the design or renovation of ACRF's and it is important they contribute knowledge of design features which can have impact on the quality of work for staff and the quality of lives for residents. There are several models of culture change and the nurse manager, who often has the responsibility for driving culture change, is a key person in determining which direction to take. $\mathrm{He} / \mathrm{she}$ has a detailed knowledge of the staff and residents, the existing culture of the environment and his/her judgement in how to facilitate culture change is paramount. Including a café in this facility was driven by the nurse manager and he/she has been able to influence the way in which it is used to meet the needs of the staff and residents. As the findings indicated, this café creates a sense of community and "doesn't get people segregated". Culture change models commonly advocate for a psychosocial climate where there is less emphasis on a hierarchical structure [32].

One of the benefits of introducing a café into an ACRF is that a café is a part of the social culture in New Zealand. Sharing food and drink at a café is an inherently social activity and a café atmosphere presses for ordinary everyday social behaviors. The café environment provides a unique opportunity for all staff to see and relate to the residents as social beings, individuals in their own right and not just figures of dependency. One important clinical implication to consider in the café environment is the need for confidentiality. The café environment provides a social environment where conversations can easily occur, however, it is also a public place and staff must be aware of the need to maintain the privacy of residents' confidential information. Staff education sessions about privacy and confidentiality, regularly held in this facility, can educate staff about being mindful of this issue in the café. A challenge for nursing and care worker staff is to replicate the tone and atmosphere of the café into the ward/unit setting, to develop a more home-like atmosphere during daily interactions with residents, rather than a hierarchical, custodial or patronizing approach. 


\section{Limitations}

This small scale qualitative descriptive study is of an exploratory nature and the results do not claim to be generalizable to other settings. Potential bias in the research findings is twofold; the participants consisted of a self-selecting group commenting about their own workplace and given anonymity is difficult to maintain in a single workplace, those who have a positive viewpoint are more likely to volunteer. In addition, data analysis did not include differentiating data according to type of staff role due to the low numbers of participants in each role category. Further research is required to explore the impact of a variety of environmental innovations with frontline staff but also those staff who service the facility. As suggested, the relationships between service staff and residents may also contribute to the residents' quality of life and further research is required to explore the range and impact of relationships between service staff and residents [33].

\section{Conclusion}

It is widely recognised that aged care facilities of the future must provide quality services which value the lives of older people and in order to achieve this, the people who work in the facility must also be recognised and valued. This research has discussed the potential of a café as a vehicle for positively influencing the experience of work for staff and findings have indicated that a café can contribute to staff satisfaction. A nurse manager who has positively influenced the experience of work for staff can do so in the knowledge that resident satisfaction will also benefit.

\section{References}

1. Brownie S, Nancarrow S (2013) Effects of person-centered care on residents and staff in aged-care facilities: a systematic review. Clin Interv Aging 8: 1-10.

2. Andrew A, Wilson LH (2014) A café on the premises of an aged care facility: morethan just froth? Scandinavian Journal of Occupational Therapy 21(3): 219-226

3. Robinson G, Gallagher A (2008) Culture change impacts quality of life for nursing home residents. Topics in Clinical Nutrition 23(2): 120-130.

4. Jones C (2011) Person centered-care: The heart of culture change. Gerontol Nurs 37(6): 18-25.

5. Kehoe M, Van Heesch B (2003) Culture change in long term care: the Wellspring model. Journal of Social Work in Long-Term Care 2(1-2): 159173.

6. Rigby J, O Connor M (2012) Retaining older staff members in care homes and hospices in England and Australia: the impact of environment. International Journal of Palliative Nursing 18(5): 235-239.

7. Kane R, Lum T, Cutler L, Degenholtz H, Yu T (2007) Resident outcomes in small-house nursing homes: a longitudinal evaluation of the initial green house program. J Am Geriatr Soc 55(6): 832-839.

8. Bergman Evans B (2004) Beyond the basics: effects of the eden alternative model on quality of life issues. J Gerontol Nurs 30(6): 27-34.

9. Grabowski DC, O Malley AJ, Afendulis CC, Caudry DJ, Elliot A, et al. (2014) Culture change and nursing home quality of care. Gerontologist 54(Suppl_1): S35-S45.
10. Junxin L, Davina P (2014) Resident outcomes of person-centered care in long-term care: A narrative review of interventional research. Int J Nurs Stud 51(10): 1395-1415.

11. Miller EA, Booth M, Mor V (2008) Meeting the demographic challenges ahead: Toward culture change in an ageing New Zealand. Australia and New Zealand Health Policy 5(5): 1-8.

12. Bengtsson A, Carlsson G (2005) Outdoor environments at three nursing homes: focus group interviews with staff. Journal of Housing for the Elderly 19(3/4): 49-69.

13. Kenkmann A, Hooper L (2012) The restaurant within the home: experiences of a restaurant-style dining provision in residential homes for older people. Quality in Ageing \& Older Adults 13(2): 98-110.

14. Palmer JA, Meterko M, Shibei Z, Berlowitz D, Mobley E, et al. (2013) Nursing home employee perceptions of culture change. Research in Gerontological Nursing 6(3): 152-160.

15. van den Pol Grevelink A, Jukema J, Smits C (2012) Person-centered care and job satisfaction of caregivers in nursing homes: a systematic review of the impact of different forms of person-centred care on various dimensions of job satisfaction. Int J Geriatr Psychiatry 27(3): 219-229.

16. Sjögren K, Lindkvist M, Sandman P, Zingmark K, Edvardsson D (2015) To what extent is the work environment of staff related to person-centered care? A cross-sectional study of residential aged care. J Clin Nurs 24(910): 1310-1319

17. Boldy DP, Chou S, Lee AH (2004) Assessing resident satisfaction and its relationship to staff satisfaction in residential aged care. Australiasian Journal on Ageing 23(4): 195-197.

18. Hrehocik M (2009) 24-hour dining feeds culture change. Long-Term living: For the continuing. Care Professional 58(9): 22-27.

19. Shield RR, Tyler D, Lepore M, Looze J, Miller SC (2014) Would you do that in your home? Making nursing homes home-like in culture change implementation. J Hous Elderly 28(4): 383-398.

20. Stone RI, Reinhard SC, Bowers B, Zimmerman D, Phillips CD, et al. (2002) Evaluation of the Wellspring model for improving nursing home quality.

21. Miller SC, Lepore M, Lima JC, Shield R, Tyler DA (2014) Does the introduction of nursing home culture change practices improve quality? J Am Geriatr Soc 62(9): 1675-1682.

22. McGilton KS, Boscart VM, Brown M, Bowers B (2014) Making tradeoffs between the reasons to leave and reasons to stay employed in longterm care homes: Perspectives of licensed nursing staff. International Journal of Nursing Studies 51(6): 917-926.

23. Kahlke R (2014) Generic qualitative approaches: Pitfalls and benefits of methodological mixology. International Journal of Qualitative Methods 13(1): 37-52.

24. Marshall M, Rossman GB (2011) Designing qualitative research $5^{\text {th }}$ edn), Sage Publications, Los Angeles, California, USA

25. Marquis R, Freegard H, Hoogland L (2004) Cultures that support caregiver retention in residential aged care. Geriaction 22(1): 3-12.

26. Eldh AC, Zijpp T, McMullan C, McCormack B, Seers K, et al. (2016) I have the world's best job' - staff experience of the advantages of caring for older people. Scand J Caring Sci 30(2): 365-373.

27. Coleman M, Looney SO Brien J, Ziegler C, Pastorino C, Turner C (2002) The eden alternative: findings after 1 year of implementation. Journals Of Gerontology Series A: Biological Sciences \& Medical Sciences 56A(7): M422-M427.

28. Chou S, Boldy DP, Lee AH (2002) Staff satisfaction and its components in residential aged care. International Journal for Quality in Health Care 14(3): 207-217. 
29. George E, Hale L, Angelo J (2017) Valuing the health of the support worker in the aged care sector. Ageing \& Society 37(5): 1006-1024.

30. Häggström E, Skovdahl K, Fläckman B, Kihlgren A, Kihlgren M, et al. (2005) Work satisfaction and dissatisfaction -- caregivers' experiences after a two-year intervention in a newly opened nursing home. Journal of Clinical Nursing 14(1): 9-19.

31. Hinman M, Heyl D (2001) Influence of the Eden Alterative on the functional status of nursing home residents. Physical \& Occupational Therapy in Geriatrics 20(2): 1-20.
32. Connor T (2016) Revolutionising aged care. Kai Tiaki Nursing New Zealand 22(10): 22-23

33. Stone R (2003) Selecting a model or choosing your own culture. Journal of Social Work in Long-Term Care 2(3-4): 411-422. (c) (i) Creative Commons Attribution 4.0

For possible submissions Click Here

Submit Article

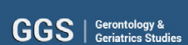

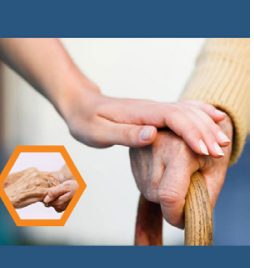

\section{Gerontology \& Geriatrics Studies}

\section{Benefits of Publishing with us}

- High-level peer review and editorial services

- Freely accessible online immediately upon publication

- Authors retain the copyright to their work

- Licensing it under a Creative Commons license

- Visibility through different online platforms 